\title{
From Resources to Intellectual Virtues: A Review and Development of the Literature on Knowledge and Organizations
}

\begin{abstract}
This paper comprehensively reviews the substantial body of research, which has evolved over the past two decades in the area of knowledge and organizations. In addition, the paper identifies an important area for future research on the interplay of ethics and epistemology. The paper takes a brief historical look at the development of the literature from within the resource-based theory of the firm and then focuses in detail on some key thematic developments, which have shifted the epistemological emphasis from resources to practices, discourses, and most recently, ethics. The review provides a synthesis and evaluation of this extensive body of research within organization and management studies as well as some of the work which it is influenced by and draws upon in the fields of epistemology (the philosophy of knowledge) as well as the sociology and psychology of knowledge. The paper then identifies potentially valuable directions for new research on the intellectual virtues.
\end{abstract}

\section{Introduction}

There have been extensive reviews of the early literature on organizational learning where the first references to learning in an organizational context are in evidence and where the emphasis is largely on individual learning (see e.g. Huber, 1991) and therefore this review concentrates on the work on knowledge 
and organizations, which places considerably more emphasis on social sources of knowledge, and can in some respects be seen as reacting against (rather than influenced by) the mentalistic approach of the early organizational learning literature. The 'resource-based theory of the firm' had a more direct influence on the discussion of knowledge and organizations, resulting in the development of a 'productive' or 'performative' epistemology and this is the starting point of this literature review. More recent trends in the literature however have seen a shift away from static approaches to knowledge as a resource (although the legacy of an instrumental view of knowledge persists) towards the study of knowing as process where the socio-material and cultural practices of knowing have been brought into sharp focus, and consideration is given to the question of who knows and who learns together within 'communities of practice'. Of particular significance is the discursive and narrative process that is at play (within and between communities of practice) as knowing takes place. Finally, the most recent developments in the literature which intersect ethics and epistemology are explored and questions for future research which concern the virtues of knowledge are established. The contribution of this paper therefore is two-fold: it provides a detailed thematic review of the literature incorporating productive/taxonomic, practice-based and narrative approaches to the topic as well as identifying an important area for further research in the interrelationship of knowledge and ethics and generating research questions on virtue epistemology. 


\section{Antecedents to the Discussion on Knowledge and Organizations}

For centuries, epistemologists were concerned with individual and rational modes of knowing, and it is not surprising therefore that the earliest literature concerning knowledge and learning in organizations is based on a mentalistic understanding of knowledge. Torres (1994, p. 328), for example, pointed out that the success of learning organizations depends on the attributes of individual employees. Similarly, Simon (1991, p. 125), influenced by research within cognitive psychology, claimed that all learning takes place inside individual human heads and an organization learns in only two ways: (a) by the learning of its members and (b) by ingesting new members who have knowledge the organization did not previously have. However, Simon does acknowledge that human learning - in the context of an organization - is very much influenced by the organization.

The above examples are but a brief selection from a vast body of literature on organizational learning, which privileges the individual knower. This research has been reviewed previously e.g. Duncan and Weiss (1979, p. 78) point out that to a very great extent the literature on organizational learning had its origins within psychology and consequently emphasizes individual learning. Nonetheless, Blackler (1995) identifies a number of images other than embrained knowledge present in the organizational learning literature, and it must be pointed out that more recently, research on 'situated learning', is social 
in nature. Shipton (2006) provides a useful typology of the organizational learning literature from prescriptive/normative approaches to more descriptive studies and from individual to organizational. Contemporary research on knowledge in organizations is critical of the mentalistic approach adopted above (see e.g. Gherardi, 2000; Cook and Brown, 1999; Hakanson 2010) and focuses instead on the social and community aspects of knowing. Petit and Huault (2008, p. 74) point out that most contemporary studies in the domain of knowledge and organizations insist on the socially constructed nature of knowledge and break with the dominant positivist paradigm.

The literature on organizational learning predated the current discussion on knowledge and organizations but as Duncan and Weiss (1979) indicate, there is at any rate, an avoidance of the word 'knowledge' within organizational learning; this early literature had scarcely a reference to knowledge. Perhaps this is unsurprising since Lyotard (1979/2004) points out that knowledge (savoir) in general cannot be reduced to learning (connaissance) and should be considered separately. Spender (2008 p. 169) postulates that although organizational learning and organizational knowledge might seem complementary, in practice the two literatures run curiously parallel and 'worshiping at different alters, honor different high priests.' Hence, although the organizational learning literature has been influential, the literature on knowledge and knowing has essentially evolved from another field of research, namely the 'resource-based-theory of the firm'. One of the earliest references to 
knowledge and organizations is evident in the work of Winter (1987), who emphasises knowledge as strategically important and refers to knowledge and competence as assets, which need to be described, understood and measured. The aim of his work is to represent knowledge in a state description; therefore, knowledge is laid out along continua ranging from highly tacit (personalized knowledge which is difficult to communicate) to knowledge which is fully articulate (and can be communicated from its possessor to another person in symbolic form). Winter's approach to knowledge and his attempt to measure it and understand its strategic value is driven by the view that knowledge is a resource capable of generating sustainable competitive advantage for the firm.

Within the resource-based theory of the firm, resources are categorized and their important characteristics described. Resource-based approaches to the theory of competitive advantage highlight four characteristics of resources which according to Grant (1991, p. 124) are important in determining the sustainability of competitive advantage: durability, transparency, transferability and replicability. Thus, the strategically important resources are those that will not depreciate or become obsolete; are difficult for competitors to identify and understand; are imperfectly transferable; and are difficult to replicate and imitate. The resource-based view quickly gave rise to the development of a related knowledge-based understanding of the firm, as clearly the knowledge possessed by the firm exhibits several desirable characteristics - 'it is differentiated, intangible, often difficult to transfer, its replication is uncertain 
requiring investment over a period of time and it is a source of first-mover advantage due to learning-by-doing' (Grant, 1994, p. x). Knowledge therefore soon came to be seen as the primary productive resource, which firms use, and so attempts were made - as we can see in the early work by Winter - to map out the dimensions of knowledge and describe its characteristics in order to place a value on it. For a detailed review of the resource-based view of the firm see Lockett et al. (2009).

The emphasis on categorizing and mapping out different types of knowledge originating from the 'resource-based view' has led to a pluralist epistemology. The resource-based view, with its emphasis on taxonomizing knowledge, has been influential in the debate on knowledge and knowing in organizations and has led to an emphasis on productivity, performativity and instrumentality, which persists in much of the literature. Sheng and Ming. (2009) offer a critical commentary on the ineffectiveness of taxonomies which fail to take account of the changing relations between knowledge assets and environmental conditions and it is also necessary at this point to mention a stream of research on organizational capabilities, closely related to the resource-based view which creates a shift from static approaches to more dynamic models of knowledge development.

Organizational capabilities are defined as 'complex bundles of skills and accumulated knowledge, exercised through organisational processes that enable 
firms to coordinate activities and make use of their assets' (Day, 1994, p. 38). Wang and Ahmed (2007, p. 35) define capabilities as a firm's ‘behavioural orientation constantly to integrate, reconfigure, renew and recreate its resources and capabilities.' The capabilities literature shifts the emphasis from a preoccupation with the specific resources available to the firm (and the specific knowledge) to a concern with what the firm is able to do. According to Grant (1991, p. 119), there is a key distinction between organizational resources and capabilities. Resources are simply inputs into the production process which alone are not very productive; rather it is capabilities that are the main source of a firm's competitive advantage. Grant suggests that resources are the sources of a firm's capabilities while capabilities are the main source of its competitive advantage which according to this view, derives from the capability to put together different pieces of knowledge and other resources. Within a resourcebased view, knowledge is immobile; it is an entity to be mapped out and measured. On the other hand, when the emphasis is placed on capabilities, knowledge is understood to be more dynamic; the concern is with 'the collective learning in the organization, especially how to coordinate diverse production skills and integrate multiple streams of technology' (Hamel and Prahalad 1990, pp. 79-91). Hence, the prominence is placed on the combination, connection and application of knowledge rather than on the prioritization of certain types of knowledge. Accordingly, the capability to generate new knowledge is of considerable strategic importance. This view has resulted in a shift of emphasis in the literature on knowledge and knowing from the description of an inactive 
resource to the development of dynamic models of knowledge generation within firms although it retains a focus on productivity and performance.

\section{'Productive' Knowledge}

The impact of the resource-based perspective has been enduring and has resulted in a productive orientation towards knowledge as well as use of the label 'knowledge management'. Gherardi (2000, p. 213) explains that the phrase 'knowledge management' unites the image of knowledge as a commodity (or asset) with that of its intentional and deliberate control. Fahey and Prusak (1998, p. 265) argues that this performative emphasis and concern with manipulating knowledge has led to a failure to distinguish between knowledge, data and information. They argue that if there is no difference between these three concepts then there is nothing new or interesting about knowledge as a topic within management studies. This point will be returned to in the final section of the paper where the argument is made for a shift towards a more reflective approach to knowledge closer to wisdom than to information. For a review of 20 of the most cited knowledge management articles, see Nonaka and Peltokorpi (2006). According to Mc Dermott (1999, p. 104), the human, community and activity aspects of knowledge distinguish it from information: 'Ironically, when we look at our expertise, the heart of knowledge is not the great body of stuff we learn, not even what individuals think, but a community in discourse, sharing ideas.' The influence of the resource-based view led many researchers to attempt to classify knowledge. Spender (1994) developed a two-by-two matrix using the 
explicit-implicit and individual-social dimensions of knowledge. It should be noted that the tacit/explicit dimensions of knowledge originally come from research within philosophy and cognitive psychology. Within philosophy, Ryle (1949) classified knowledge into categories of knowing that something 'exists' and knowing 'how' it operates. Similarly, James (1950) differentiated 'knowledge about', which is abstract and the result of reflection, from 'knowledge of acquaintance', which results from experience. In addition, there is Polanyi's distinction between tacit knowledge and knowledge that is fully articulate. According to Polanyi (1966), in all cases of personal knowing, a set of rules are observed which are not known as such to the person following them and therefore cannot easily be documented for others to follow.

Spender $(1994,1996)$, using the explicit-implicit and individual-social dimensions of knowledge, has designated several different types of knowledge: 'conscious' knowledge, which can be reported explicitly by the individual members in the organization; 'automatic' knowledge, which individual members bring to the creation of practice but are unable to report; 'objectified' knowledge that is wholly explicit and diffused through the organization; and 'collective' knowledge, which forms the taken-for-granted context of organizational activity. The taxonomizing continued with work such as Boisot (1995, p. 145), who used the terminology of codification (which relates to whether or not knowledge can be stored or written without incurring unnecessary information loss) and diffusion (which relates to the degree to which knowledge can easily be shared) 
to develop a similar classification: 'public' knowledge, which is codified and diffusible and assists in the creation of new knowledge through combination; 'common sense' knowledge, which is acquired over a lifetime through experiences and interactions; 'personal' knowledge, which is more idiosyncratic and more difficult to articulate than common sense knowledge since it arises out of the individual's own experience that is not available to others; and finally, 'proprietary' knowledge, which a person or group develops and codifies in order to understand particular situations or events. Building on Boisot's classification, Choo (1998) differentiates knowledge into tacit knowledge, explicit knowledge and cultural knowledge. Cultural knowledge consists of 'the cognitive and affective structures that are habitually used by organizational members to perceive, explain, evaluate and construct reality' (Choo 1998, p. 112). Zarzabkowski et al (2010, p. 1190) distinguish between conceptual (theoretical knowledge as a way of thinking about or representing the practical world), symbolic (knowledge adopted in order to legitimize preferred practical action), and the purely instrumental (the direct application to practice) approaches to knowledge in practice.

The above are but a brief selection from the range of taxonomies developed and indeed some of these individually have been the subject of critical reviews e.g. Gourlay's 2006 critique of Nonaka's theory of knowledge creation. The taxonomic approach, although heavily criticized (e.g. Tsoukas 1994 accuses management researchers of relentless classification), nonetheless heralded a 
pluralist epistemology as opposed to the monist epistemology (rationalism) evident in so much of the earlier organizational learning literature. It also shifted the emphasis from individual to social knowledge and from explicit to tacit knowledge. Spender (1996, p. 52) argues that collective knowledge is 'more secure and strategically significant' than individual knowledge which is inherently transferable, and calls for management research to concentrate on studying what functions in firms to enable collective learning to take place, and collective knowledge to be retained and applied. Tacit knowledge is also seen as important because it exhibits all of the characteristics of superior resources. Starbuck (1992) emphasizes the economic significance of esoteric knowledge over common knowledge: (a) it is difficult for competitors to identify and understand, and (b) it is imperfectly transferable and difficult to replicate and imitate. Some researchers have noted that knowledge can possess both of the above desirable characteristics, being at once tacit and collective. For example, Choo (1998, p. 117) suggests that teams as well as whole organizations can possess tacit knowledge: 'knowledge which is hard to document but is dispersed among multiple actors who interact with each other and with the physical, cultural, and social dimensions of their task and organizational setting.' Similarly, Brown and Gray (1995, p. 80) explain that in groups, tacit knowledge resides in the "distinct practices and relationships that emerge from working together over time'. 
This 'productive' or instrumental approach to knowledge has in recent times received criticism for a number of reasons not least, because certain types of knowledge (e.g. tacit and collective knowledge) are given priority over others as well as certain professions over others. Blackler (1995) refers to the preferential treatment given to 'knowledge workers' and 'knowledge-intensive firms' and the resultant lack of concern for 'everyday knowledge' in organizations and 'how it comes about'. Hislop (2008, p. 579) similarly argues that the term 'knowledge work' is reserved for occupations which involve the intensive and extensive use of knowledge for example professional, managerial and creative workers such as management consultants, architects, software designers, scientists and engineers (for research on management consultants see e.g. Kelley 1985; Alvesson 1993, 1995, 2001; Kitay and Wright 2007). Lave (1996) points out that the boundaries of knowledge are fluid and overlapping and hence it is inappropriate to conceive of them as separate and to focus on one type of knowledge. Similarly, Robertson and Swan (1998, p. 548) are critical of the overemphasis of 'discrete, and relatively stable types of knowledge' and the neglect of more 'fluid, emergent, action-based processes of knowledge creation, articulation and communication'. These criticisms have been considered and, combined with the shift in emphasis from resources to capabilities referred to already, we see the development of more dynamic models of knowledge creation (even if for the most part they remain focused on productivity and performance). 
Nonaka $(1994,1996,1998)$, in a similar vein to the models discussed above, distinguished between tacit and explicit knowledge but using the distinction, advanced the discussion through arguing that it is the continual dialogue between explicit and tacit knowledge which drives the creation of new ideas and concepts. Knowledge is treated as emerging, and the oft-cited 'spiral' model of knowledge creation (later referred to as the SECI Model, e.g. Nonaka 1998) identifies four different patterns of interaction between tacit and explicit knowledge. These patterns represent ways in which existing knowledge can be 'converted' into new knowledge. The notion of knowledge creation developed here is akin to Anderson's (1983) model in cognitive psychology whereby declarative knowledge has to be transformed into procedural knowledge in order for cognitive skills to develop. However, in Anderson's model the transformation of knowledge is unidirectional whilst Nonaka's model involves a two-way flow between tacit and explicit knowledge. The four different modes of knowledge conversion are as follows: Socialization (from tacit to tacit knowledge, which occurs through interaction between individuals, i.e. through observation, imitation and practice); Combination (from explicit to explicit in which individuals exchange and combine knowledge through social processes such as meetings and conversations ;); Externalization (from tacit knowledge to explicit knowledge. Metaphor plays an important part in the externalization process); and Internalization (from explicit to tacit knowledge - this bears a resemblance to the traditional notion of 'learning'. Action is deeply related to the internalization process). 
Later Nonaka and Konno (1998) offer the concept of BA as an integrating conceptual metaphor for the SECI model. Within BA, knowledge creation is achieved through self-transcendence. For example, originating BA is the space wherein individuals share feelings, emotions and mental models enabling synchronising behaviour and improvisation. From originating BA emerge care, love, trust and commitment. This is where knowledge creation begins. The centrality of care and trust to knowledge creation is an important point which we will consider further in the final section of the paper on epistemology and ethics. In a similar vein to Nonaka, Hedlund (1994) attempted to build a model of knowledge management based on the interplay between articulated and tacit knowledge at four different levels - the individual, the small group, the organization and the interorganizational domain. Articulated and tacit knowledge exist at all four levels. The model depicts knowledge types, and transfer and transformation processes, and illustrates the movement towards a more dynamic, processual and dialogic understanding of knowledge in organizations. Tsoukas (2009, p. 942) however argues that whilst the above research suggests that dialogue is an important mechanism through which new knowledge emerges, it has not been adequately theorized. Spender (1996, p. 54) also called for a dynamic theory of the firm, pointing out that we must move 'beyond the argument so far, that organizational knowledge is of two static types, explicit and tacit or of four static types, conscious, automatic, objectified and collective' and that the focus must be on their interaction. 
It should be noted, however, that serious critique of this literature has occurred which suggests that Polanyi's original work has been misinterpreted by management writers who fail to understand that tacit knowledge, due to its very nature, cannot become explicit. Cook and Brown (1999) argue this point and present an alternative view, returning us to the distinctions between knowledge types and illustrating Gabriel's (2000, p. 59) point that 'classification and theory stand in mutual definition, continuously redefining each other'. Cook and Brown (1999, p. 382) describe an 'epistemology of possession' and argue that each of the four categories of knowledge inherent in the explicit/tacit and individual/group distinctions is 'a distinct form of knowledge on equal standing with the other three'. They posit that each form of knowledge 'does work that the others cannot' and therefore one form of knowledge cannot be changed into another: 'tacit knowledge cannot be turned into explicit, nor can explicit knowledge be turned into tacit.' Similarly, they argue that individuals and groups each do epistemic work the other cannot. Moreover, Cook and Brown (1999, p. 386) suggest that the above four types of knowledge do not capture everything we know, for in addition to knowledge there is knowing, and knowing is epistemically distinct. They distinguish the epistemology of possession (which comprises the four different types of knowledge from the explicit/tacit and individual/group distinctions) from the epistemology of practice which comprises knowing, that relates to the epistemological dimension of action. Indeed many researchers in the area of knowledge and knowing in 
organizations have come to understand knowledge as a process and to focus on how knowing comes about. The next section considers these works which are based on process epistemologies, although many of these researchers see knowing and doing as inseparable and do not distinguish between knowledge and knowing as Cook and Brown do. For example, Kamoche and Maguire (2010) argue that the knowledge of subterranean workers cannot be divorced from their practices and material artefacts. In this paper however, I concur with Cook and Brown and retain the overall term knowledge rather than knowing as I believe that knowledge exists outside of doing. The next section however, reviews process literature which favours the concept of knowing over knowledge and sees knowing as intimately connected with practice.

\section{Process and Practice-based Epistemologies}

This section illustrates the shift in understanding from knowledge as 'a productive resource' to knowledge (or rather 'knowing') as 'a process'. Blackler (1995, p. 859) advocates that 'the somewhat static concept of 'knowledge' be replaced by the more dynamic concept of 'knowing', Choo (1996) describes a 'knowing organization' which incorporates sensemaking, knowledge building and decision-making processes, while Spender (1996, p. 55) views the firm as 'a system of knowing activity' rather than as 'a system of applied abstract

knowledge'. More recently, Patriotti (2003, p. 350) suggests that the conceptualisation of knowledge as commodity has 'divorced knowledgeoriented phenomena from human action and the intricacies of everyday 
practice'. The above are but a few of the many researchers whose work focuses on the construction and practice of knowing in organizations. Researchers have drawn on a variety of process- (knowledge as a process of construction) and practice- (knowing as activity) based epistemologies, including constructivism, activity theory and communities of practice. This section briefly discusses these approaches.

Tsoukas (1996), Spender (1996), Gherardi and Nicolini (2000), Suchmann (2000), and Hakanson (2010) have drawn on constructivist (and other processbased) studies in order to help understand the process through which knowledge is constructed in organizations. Constructivism provides a well-developed and robust theory which argues that scientific knowledge (indeed all knowledge) is constructed (rather than, say, being discovered or the product of rational activity). The origins of the phrase 'social construction' are usually traced to Berger and Luckmann (1966), who argued that reality is socially constructed. They placed particular emphasis on institutions which are maintained through processes of socialization and legitimation and which are described as having reality. However, it is the constructivism studies within the sociology of scientific knowledge that have had most influence within organization and management studies. Petit and Huault (2008) argue that researchers on organizational knowledge for the most part focus on knowledge complexity and its socially constructed side. For constructivists within the sociology of scientific knowledge (SSK), outcomes - scientific facts and knowledge - are the 
result of an interactive and sensemaking process between participants and the consequential methodological imperative is that the practices and discourses of actors should be studied in close detail over an extended period. Thus, the detailed description and analysis of settings where knowledge is constructed such as a laboratory - are a distinctive hallmark of the constructivist tradition within SSK (Latour, 1987; Law, 1994). Latour and Woolgar's (1986) laboratory life is perhaps the best known of these ethnographic studies which seek to understand the workings of the scientist and the dealings involved in the construction of facts and knowledge. Later, though, Merz and Knorr-Cetina (1997) attempted to apply the empirical approach of the laboratory studies to a 'thinking science' - theoretical physics. Their study yields 'layers of methodical policies, 'ansatze', tricks and other devices, which are piled into doing a theoretical computation' (Merz and Knorr-Cetina, 1997, p. 74). It should be observed that as well as epistemologies, constructivism sometimes refers to theories, social objects or things; it can be an ontological programme with the focus on social objects and laboratory artefacts or one with the focus on the natural world, or it can be an epistemological project, when the focus is on knowledge (Sismonda, 1993, p. 547).

A significant influence on SSK was Bloor's (1976) principle of symmetry, which holds that both true and false knowledge need a sociological explanation. There should be no a priori reason for seeking a different explanation for rational 'scientific' beliefs as against mythical beliefs. The principle contends 
that there is no difference between scientific knowledge (facts) and other forms of knowledge (fictions); hence, Bloor argued that the sociologist should analyze theories symmetrically and impartially irrespective of their perceived truth or rationality. Knorr-Cetina (1994) points to the presence of fictions as well as facts in institutional life: 'modern institutions, I want to claim, continually produce fictions, steer their way through fictions, work with fictions and become founded upon fictions' (Knorr-Cetina, 1994, p. 8). According to Knorr-Cetina (1983), we need not postulate that scientific theories are true, but only that they are successful. Construction here refers to the negotiations and dealings that are required to transform a claim into a 'taken-for-granted object'; ' '...the emphasis is on the 'literary', rhetorical and persuasive techniques that are needed to convince the community' (Sismondo, 1993, p. 530, emphasis added).

The influence of constructivism has resulted in research akin to the laboratory studies where the process of knowledge construction in organizations is ethnographically studied. Examples of such work include Suchmann's (2000) study of civil engineers engaged in designing a bridge which illustrates how discursive and material elements are brought together in the construction of organizations and artefacts. Suchmann (2000, p. 312) places the emphasis not on the content of the engineers' knowledge, but on the way they talk among themselves and with other relevant parties, and on how they transform their own embodied courses of action into codified documents and other materializations. Similarly, Gherardi and Nicolini study how safety knowledge is 'constituted, 
institutionalised, and continually redefined and renegotiated' through the interplay of action and reflexivity (Gherardi and Nicolini, 2000, p. 329). More recently, Kamoche and Maguire (2010) study the everyday practice of miners and describe 'pit sense' which is a form of knowledge which is largely tacit and which is constituted by tunnellers as a way to negotiate their everyday work practices as they determine acceptable levels of risk in a harsh subterranean environment 'in practice, pit sense is not acquired through formal training, but is disseminated in situ, experientially, informally, through close social interaction and use of language, and based on the very unambiguous norm of safety.' (Kamoche and Maguire, 2010, p. 726-727).

An alternative process-based approach that has also had some influence in organization studies is activity theory (see e.g. Blackler, 1993, 1996, 2000). In order to consider how activity theory is seen to differ from other approaches to knowledge, including constructivism, it is useful to refer to Engstrom's (2000, p. 301-302) (originally cited in Weick, 1979, p. 1) example of three umpires 'calling balls' in a foul. The first umpire calls them 'as they is' (this umpire 'sees himself as the center in that it is he who performs, registers and with his whistle makes public the objective state of reality'); the second umpire calls them 'as I sees them' ('sees herself specifically as the central interpreter of ambiguous events'); and the third umpire claims that 'they ain't nothin' till I calls them' ('believes that it is he who by virtue of his social position constructs in a compelling manner the social reality'). Engstrom maintains that activity theory 
differs substantially from the aforementioned epistemologies and needs a fourth umpire since the above do not adequately take into account collective action and 'foul ball' can be better explained to happen collectively:

it is achieved by the interplay of the pitcher, the hitter, other players, coaches, the umpire, and the spectators - not to mention the bat, the ball, the gloves, and the field ... the umpire would not get that constructionist moment of omnipotence, in fact, the very umpire would not exist, if the activity system of baseball had not been collectively constructed, both historically and in the specific spatial-temporal situation. (Engstrom, 2000, p. 307)

Blackler $(1993,1996)$ traces the intellectual origins of activity theory from Marx to Vygotsky, Leont'ev and Engstrom. Marx (see e.g. Marx posited that people construct themselves and the social world, in which they live through practice, and that human nature is not fixed - it evolves dialectically through labour. Later Vygotsky (see e.g. Vygotsky, 1978) draws on Marx's notion of human nature and postulates that human psychology develops when a subject pursues objects (goals) mediated by tools (language, technology, etc.), thus portraying a view that diverges from 'mainstream' psychology in that it does not separate mental/cognitive development from practical activity. Leont'ev modifies Vygotsky's notion of mediation to include a social dimension and distinguishes actions (which are carried out by individuals) from activities (the social objects or purposes actions serve to achieve) (see e.g. Leont'ev, 1978). Finally, Engstrom (e.g. Engstrom, 1987, 1999, 2000) conceptualises the temporal and 
change-oriented nature of human activity and claims that the 'germs' of social change are present in any activity system. The researcher's role is to engage in critical praxis - highlighting contradictions and helping participants to see the potential for development. The researcher must study the rules of interaction, and the socio-cultural-historical context that shapes/is shaped by the activity system. See Blackler $(1993,1996)$ for a detailed discussion of the contribution of the above theorists.

Taking activity theory into the organizational arena has led to a conceptualization of knowing in practice. For the most part, researchers here refer to knowing rather than knowledge, and knowing and doing are not conceived of separately. However, there is possibly a need for some greater discussion and clarification around this issue and for further engagement with Cook and Brown's (1999) view of the possibility of knowledge and knowing as epistemically distinct categories with knowing as the epistemological dimension of action. Blackler (1995, p. 1039) argues that from an activity theoretical perspective, knowing in all its forms is analyzed as a phenomenon which is (a) manifest in systems of language, technology, collaboration and control (i.e. it is mediated); (b) located in time and space and specific to particular contexts (i.e. it is situated); (c) constructed and constantly developing (i.e. it is provisional); and (d) purposive and object-oriented (i.e. it is pragmatic). Blackler cautions us, however, to the lack of attention given by activity theorists to the notion of power, and therefore to the above list he adds that knowing is also (e) contested. 
The analysis of knowing as mediated, situated, provisional, pragmatic and contested provides a basis for identifying research priorities. For example, Blackler suggests that detailed ethnographic studies are needed to illuminate the ways in which people improvise, communicate and negotiate within expanded activity systems; investigation is also required based on the anxiety that individuals and communities may experience in the face of significant, ongoing and perhaps conflicting demands for changes in their work methods and priorities; and issues of domination and subordination and their relation to knowing and learning also require further discussion. Mork et al. (2010) take up Blackler's challenge on the contested nature of knowledge, illustrating how contests of power are played out in practice in the study of medical innovation processes. They argue that innovations are non-linear and interactive processes in which negotiations of interests play a crucial role (Mork at al. 2010 p. 578). Kamoche and Maguire (2010, p. 739) also address the politics of knowing in a study which demonstrates how the tacit knowledge of everyday practice comes under threat with the introduction of bureaucratic procedures rationalized on the basis of commercial outcomes highlighting the 'contested and multi-faceted nature of contests over the meaning and sustainability of knowledge.'

Finally, and arguably even more influential on organization studies, is the literature on communities of practice, which also focuses on the contextually mediated nature of work and learning, and which is founded upon Lave and Wenger's $(1990,1996)$ practice-based theory of learning as 'legitimate 
peripheral participation' in 'communities-of-practice'. Lave and Wenger's work concentrates on the relationship between learning and the social situations in which it comes about through co-participation. Organizational researchers such as Brown and Duguid $(1991,1998)$ draw on Lave and Wenger's work to develop their learning-in-working view which relates the social and collaborative nature of learning within communities of practice. A community of practice develops a 'world view' or shared sense of what it does and of how to do it and what the criteria for judgement are. Wenger (2000, p. 220) suggests that communities of practice be assessed in terms of 'enterprise' (the level of learning energy present), 'mutuality' (the depth of social capital) and 'repertoire' (the degree of self-awareness). Wenger (2000, p. 227) further argues that there are three modes of belonging to communities: (1) engagement (doing things together, talking, producing artefacts) (2) Imagination (constructing an image of ourselves, of our communities, and of the world, in order to position ourselves, to reflect on our situation, and to explore possibilities) and (3) alignment (making sure that our local activities are sufficiently aligned with other processes so that they can be effective beyond our own engagement). The literature on communities of practice argues that communities are the cornerstone of a social learning system.

Communities of practice, although powerful sources of knowledge, can easily be blinkered by the limitations of their own world view and hence, research focuses on knowledge development between communities, as well as on knowledge 
development within communities, arguing that organizations are not single communities of practice, but rather, hybrid groups of overlapping and interdependent communities (Brown and Duguid, 1998, p. 97). In this view, competitive advantage relies on the continuous generation and synthesis of collective organizational knowledge developed within and between communities of practice in organizations. More recently, Hakanson (2010, p. 1801) argues that knowledge transactions that take place within epistemic communities can be accommodated equally well and often better, in other institutional settings such as those of markets, guilds, or universities. Indeed, he suggests that firms often become epistemic communities in their own right.

Brown and Duguid (1998) posit that knowledge moves differently within communities than it does between them as different communities of practice have different principles and priorities. They offer strategies for promoting the spread of knowledge between communities which they describe in terms of 'translation', 'brokering' and 'boundary objects'. Translators can frame the interests of one community in terms of another community's perspective whereas knowledge brokers are involved in participation rather than mediation and work simultaneously in different communities. Finally, boundary objects are objects of interest to each community involved but viewed or used differently by each one; they can be physical objects, technologies or techniques shared by the communities or stories told but interpreted differently by different communities. Boundaries are one of the constitutive elements of social learning systems, 
connecting communities and offering learning opportunities.'(Wenger, 2000, p. 229).

Gherardi and Nicolini (2002) examine how conversation occurs between two or more communities of practice that are both independent and interdependent. They argue that such a focus shifts the discussion away from the "consensual and predominantly harmonious' aspect of knowing to the 'dark side of the effort to understand across boundaries - what remains not understood, what is misrepresented or ignored' (Gherardi and Nicolini, 2002, p. 420). Practice, according to Gherardi and Nicolini, is mediated by comparison among different perspectives on the world made possible by discourse, and discourse is itself understood as a practice. Moreover, discourse is generative of other practices and is a powerful means of ordering, distinguished by its capacity to handle both coherence and incoherence. Learning, according to Gherardi and Nicolini then, involves locating oneself within a discourse as well as being responsive to boundaries and differences. Mork et al. (2010 p. 588) illustrate how contests of power play out in and across communities of practice in a study of medical innovation process. Their case illustrates how negotiating becomes a central aspect of practicing and they argue that both inter- and intra-professional dissonances need to be addressed. The above discussion illustrates the shift of focus by management researchers from an understanding of knowledge as a static resource towards an emphasis on the process through which knowing comes about. There are numerous other epistemologies that focus on a process 
and/or practice such as situated learning, which is closely linked to the discussion on communities of practice and emphasizes the importance of the contextual dimension of knowing (see e.g. Tyre and Von Hippell (1997) and Bresnen et al. (2004). In addition, autopoiesis theory views organizations as selfgenerating systems and focuses our attention on the internal process through which knowledge is constructed and in particular, on languaging, the process through which knowledge brings forth a world (see e.g. Marturana and Varela, 1987; Becker, 1991; Von Krogh et al., 1994). Regardless of which of these theories have been drawn upon, it is interesting to see that they all variously emphasize the significant relationship between narrative and knowledge. As pointed out, in constructivist studies rhetoric and persuasion play a key role in convincing laboratory communities of scientific facts. Suchmann's ethnographic study of bridge-building similarly emphasizes that the best design is the one that is surrounded by the most 'convincing story'. Although there may be slightly less emphasis on language in activity theory, nonetheless knowing for Blackler is about 'perspective' making, taking and sharing, and here language plays a key role. Tsoukas (2009) discusses the embeddedness of practitioners in discursive practices. For researchers on communities of practice, language and narrative play a significant role in terms of connecting knowledge within and between communities, and it is not surprising therefore that narrative knowledge has become the focus of management researchers. Narrative knowledge in its own right has generated a substantial body of management and social science research. 


\section{Narrative Knowledge}

White (1987, p. 215) has investigated the etymology of 'narrative', tracing it to the Sanskrit gna meaning 'know' and the Latin words for both 'knowing' (gnarus) and 'telling' (gnaro). Abbott (2002, p. 11) explains that this etymology catches the two sides of narrative: it is a universal tool for knowing as well as telling, for absorbing knowledge as well as expressing it. Narrative and knowledge are intimately connected, and the discussion on knowledge and knowing in organizations necessitates an understanding of narrative and discursive processes and how they operate. Researchers in the area of communities of practice, which concentrates on the development of knowledge within and between communities, demonstrate a keen interest in narrative. Indeed, Brown and Duguid draw extensively on Orr's $(1990,1987)$ ethnographic work on photocopier repair technicians wherein the know-how of the technicians is constructed collectively through storytelling. In Orr's study, as the technicians work together on a broken machine, they tell stories in order to design a solution and these stories facilitate collective action (they are used in the future in similar diagnostic situations). The technicians continuously swap 'war stories' about malfunctioning machines and the knowledge they create is far more sophisticated and useful than anything in the formal documentation they receive. Stories 'function, rather like the common law, as a usefully underconstrained means to interpret each new situation in the light of accumulated wisdom and constantly changing circumstances' (Brown and Duguid 1991, p. 178). 
Moreover, the narratives of the technicians are shared; problem solving is collective, not individual, and the insights generated are not private but socially constructed and distributed.

Orr's work focused on narrative knowledge and further work followed in a similar vein, emphasizing narrative knowing in practice. Patriotti (2003) explores the role of narratives in organizational inquiry and knowledge work in the setting of a traditional pressing plant. Like Orr, he centres on the process through which breakdowns are investigated and solutions found. Patriotti argues that the investigation is treated as a murder case and a detective story is constructed (detective stories essentially being a process of emplotment). Narratives offer an essential vehicle for capturing this commonsensical everyday character of organizational knowledge, given that they deal with the politics of meaning, i.e. how meanings are selected, legitimised, encoded, and institutionalised at the organizational level (Patriotti, 2003, p. 352, emphasis added).

Boland and Tenkasi (1995) focused on knowledge-intensive firms and on the significance of narrative in the processes of perspective making and perspective taking. Perspective making, according to their view, involves communication that strengthens the unique knowledge of a community, whilst perspective taking involves communication that improves a community's ability to take the knowledge of other communities into account. Boland and Tenkasi suggest that 
perspective making and perspective taking are achieved by narrating experience as well as by rationally analyzing it, and that narration of experience is a critically important but often overlooked aspect of knowledge production in knowledge-intensive firms. In keeping with a Wittengsteinian view, they contend that language games are the basis for all we know. Through action within communities of knowing, we create and re-create language and knowledge; the limits of our language are the limits of our knowledge since we can explain the world only through language and narrative forms:

\footnotetext{
'Knowledge evolves by inventing new language and narrative forms. Re-narrativizing the familiar or coming up with narratives that explain the unfamiliar is the primary activity by which new knowledge comes about' (Boland and Tenkasi, 1995, p. 354).
}

The significance of narrative knowledge and the importance of narratives and stories in the greater study of contemporary organizations have been well recognized. Discussions have been influenced by the wider body of research on narrative knowledge within sociology, psychology and philosophy and it is useful here to reflect briefly on those works which management researchers have found most useful.

Bruner (1986), within psychology, argues that there are two modes of knowledge construction, each providing distinct ways of ordering experience and constructing reality - the argument and the story. Fisher's (1987) narrative paradigm reconceptualizes humankind as storytellers (homo narrans) and claims 
that the world as we know it is a set of stories. Foucault (1972) posits that knowledge is constructed through discourse and that in fact the human subject is created by discourse. Laclau and Mouffe (1985) argue that all knowledge is located within discourse but maintain that an external 'reality' exists independently - 'of course earthquakes exist but it is their construction in discourse that determines whether they are 'movements of tectonic plates' or 'manifestations of the wrath of the gods' ' (Laclau and Mouffe, 1985 p. 105). McClosky (1990, p. 96), within the study of economics, argues that economic and scientific research utilizes a variety of rhetorical figures and relies heavily on stories, metaphors, facts. Polkinghorne (1988), in studying the practice of psychotherapy, found that practitioners probe case histories and use narrative explanations to understand why the people with whom they work behave the way they do.

The narrative construction of medical knowledge has received explicit attention. For example, Hunter (1991/1993), in her need to make sense of the knowledge necessary to practise medicine, stumbled on its narrative nature. Her account of medical knowledge begins with the patient's story, the story of a set of symptoms which 'gives the patient good standing in the world of the ill'. The Physician interprets the story and transmits it into medical knowledge. The story is eventually returned to the patient as a diagnosis - 'an interpretive retelling that points towards the story's ending' (Hunter, 1991, p. 5). 
Philosophers have for centuries concentrated on individual sources of knowledge such as reason, perception and memory. However, more recently, attention has been focused on social sources of knowledge such as narrative. Examples include Ricoeur $(1984,1991)$ and Arendt $(1958$, p. 72$)$, who argues that 'the chief characteristic of the specifically human life ... is that it is always full of events which ultimately can be told as a story...' Barthes (1966/1977, p. 79) presents narrative as possessing a powerful role in society, ever-present in every social group 'narrative is international, transhistorical, transcultural: it is simply there like life itself.' Lyotard (1984, p. 23) declares that narratives are the communal method by which knowledge is stored and exchanged: 'they thus define what has the right to be said and done in the culture in question, and since they are part of that culture, they are legitimated by the simple fact that they do what they do'. In Lyotard's view, narrative is a form of knowledge, and a narrator is one 'who knows'.

Drawing on some of the above sources, management researchers have turned their interest to narrative knowledge. Czarniawska (1993, 1997, 1998, and 2003) called for a redeeming of narrative knowledge in humanities and social sciences in general and in organization studies in particular (Czarniawska, 1993, p. x). She draws on Bruner's $(1986,1990)$ distinction between the narrative mode of knowing and the paradigmatic mode of knowing in order to establish narrative as a legitimate source of knowledge. Narrative, since it does not require proof, allows for the negotiation of meaning. The method of negotiating and 
renegotiating meanings through narrative interpretation is one of the significant achievements of human development (Bruner, 1990, p. 67 quoted in Czarniawska, 1993). However, Czarniawska is at once keen to de-emphasize the distinction between scientific and everyday knowledge, or between syntagmatic construction which uses metonymy (thus based on our sense of part and whole) and paradigmatic construction which uses metaphor (thus based on our sense of like and unlike, similarity, analogy). Narrative and scientific knowledge therefore are not so far removed. Drawing on McClosky's (1990) study, Czarniawska points to how science can be said to use a tetrad of rhetorical figures - stories, metaphors, facts and formal logic - between which there is no clear separation: 'formal logic' blends into 'tales' via 'common sense logic', whereas well-used metaphors become 'facts' (Czarniawska, 1998, p. 4). We recognize a scientific text not because of its intrinsic scientific qualities, but because the author claims it is scientific (and this claim can be contested) and because he or she uses textual devices that are conventionally considered scientific (and this convention is contested all the time) (Czarniawska, 1998, p. 8).

Similarly, it is possible to collapse the division between the story and the metaphor or between prose and poetry, as McClosky (1990, p. 96, quoted in Czarniawska, 1988, p. 5) points out: 'stories criticize metaphors and metaphors criticize stories'. Czarniawska (1998) calls for a redeeming of literature in social science and organization studies, for literature emphasizes what the professional- 
scientific literature fails to capture - the everyday, the emotional, the subjective and the ethical aspects of organizational life. But, as Czarniawska notes, not only established literature can do this, it can also be achieved through a focus on organizational stories.

Storytelling is a prominent feature in the literature on organizational sensemaking. Choo (1998) sees sensemaking as one aspect of the knowing organization (the knowing organizations involves sensemaking, knowledgebuilding and decision-making processes). In turn, the literature on organizational sensemaking (e.g. Huber and Daft, 1987; Fay, 1990; Gioia and Chittipeddi, 1991; Weick, 1995, 2001) sees storytelling as a key component. Weick, perhaps the foremost advocate of the sensemaking perspective, identifies seven properties of sensemaking that emphasize that it is grounded in identity construction, retrospective, enactive of sensible environment, social, ongoing, focused on and by extracted cues, and driven by plausibility rather than accuracy. He compares the task of sensemaking to that of cartography: the sensemaker seeks to convert 'a world of experience into an intelligible world' (Weick, 2001, p. 9).

The central problem of sensemaking is the desire to create a coherent and plausible account of what is going on without ever really seeking a single true and final picture of how the world actually is. Organizations are conceived as sensemaking communities where organizational members make sense of their 
environment in order to develop a shared interpretation that can serve as a context for organizational action. Weick details how sensemaking occurs through four interconnecting processes: ecological change (sensemaking begins when there is some difference in the environment); enactment (in enacting the environment some elements of the change are isolated and bracketed for closer examination); selection (cause maps that have proven sensible in explaining previous situations, and are now superimposed on the current context to determine if they can provide a reasonable interpretation of what has occurred); and retention (the products of successful sensemaking are retained for future use). The crucial imagery portrayed in sensemaking is the impression that 'there is nobody here but us scratching around trying to make our experience and our world as comprehensible to ourselves in the best way we can, that the various kinds of order we come up with are a product of our own imagination' (Fay, 1990, p. 38). What is significant in sensemaking is plausibility rather than accuracy and hence stories play a key role. Narrative process and how they operate must play a central role in understanding how knowledge is created and shared within and between communities and organizations. Although the above literature makes a case for the importance of narrative further investigation on narrative persuasion would be fruitful.

The sections above trace the origins of the discussion of knowledge in organizations from the performative emphasis originating with the resourcebased perspective to the everyday social and discursive aspects evidenced in the 
practice and narrative-based work. In the latter work, the political and emotional aspects of knowledge sharing and creation are considered but what is largely absent is a discussion of the ethical nature of knowledge and organizations. Indeed, Aristotle argued that to be persuasive, one must exhibit phroenesis, arête and eunoia i.e. be sensible, virtuous and trustworthy. The next section explores the connection between epistemology and ethics and develops some research questions, which would result in a more robust treatment of knowledge and organizations. A focus on narratives inevitably draws us closer not just to the emotional aspects of organizational life but also to the ethical and therefore a focus on ethics is a sensible development from discursive and narrative approaches to understanding knowledge and organizations. Moral philosopher Alastair MacIntyre sees the connection between stories, ethics and knowledge and argues that stories as central to educating us in the virtues:

\footnotetext{
'Hence there is no way to give us an understanding of any society, including our own, except through the stock of stories which constitute its initial dramatic resources. Mythology, in its original sense, is at the heart of things...the telling of stories has a key part in educating us into the virtues.' (MacIntyre, 1981/1985, p.216)
}

\section{Ethics and Epistemology}

The literature on knowledge and organization has carefully considered the political, discursive and emotional practices in knowledge creation and sharing. What is largely absent from the discussion is the ethical aspect of knowledge and the interrelationship of epistemology and ethics. This absence may on one 
hand seem surprising in light of the significant emphasis on business ethics generally in the wake of high-profile financial scandals such as Enron, WorldCom, and Société Génerale. On the other hand, perhaps it is not so surprising when one considers that even for epistemologists, this interrelationship remains largely underexplored despite the fact that 'the deepest disputes in epistemology focus on concepts that are quite obviously ethical and are often borrowed directly from theoretical moral discourse' (Zagzebski, 1996, p. xxi). Within the literature on knowledge and organizations, there have been occasional and tentative references to ethical issues in knowledge creation and sharing and this forms a useful starting point for future research. For example, Miller (2008, p. 944)) points out that 'the compulsion to learn and share knowledge with others gives rise to ethical obligations' and Nonaka and Konno's (1998) originating BA (discussed earlier), generates love, trust and commitment which in turn facilitates enhanced sharing of knowledge. Drawing on Nonaka and Konno, Von Krogh. (1998) begins to explore the ethical concept of care in his search for enabling conditions for knowledge. Care is defined as serious attention (heed), a feeling of concern and interest (Von Krogh, 1998 p.137), and it is argued that care is central to developing healthy social relations, which in turn enables organizational members to share their personal knowledge and to discuss their ideas and concerns. Von Krogh. argues that "care gives rise to particular behaviour in relationships namely, mutual trust, active empathy, access to help, lenience in judgement, and courage'. Styhre et al. (2002, p. 503) similarly argue that 'care, the ability to establish interpersonal, 
sensemaking mechanisms, is the underlying key factor behind knowledgecreation in team-based organizations'. The above authors introduce us to the importance of care but clearly further conceptual work is required here. This is where Heidegger's (1962) work on care in Being and Time may prove to be particularly important with detailed conceptualization of care and consideration of the significance of care to our very existence 'by working out the phenomenon of care, we have given ourselves an insight into the concrete constitution of existence' (Heidegger, P.275, H 231). Care ethics is valuable because it emphasises relational qualities but in the context of knowledge creation and sharing, this paper argues that a more comprehensive coverage of ethical dimensions must also consider other ethical theories. Of particular relevance to the debate on knowledge is virtue ethics where specific attention is given to intellectual virtues. In Virtue-based ethics (sometimes called aretaic from the Greek arête translated as 'excellence or virtue') morality is internal and the key to good lies not in rules or rights, but in the classic notion of character (honesty, fairness, compassion, and generosity). According to Stephens (1882), the morality should be expressed in the form 'be this,' not in the form 'do this'. Rather than viewing the heart of ethics to be in actions or duties, virtue-based ethical systems centre on the agent, the character and dispositions of persons. Contemporary epistemologists such as Sosa (1980) who introduced the term 'intellectual virtue' refer to reliable belief-forming faculties and Zagzebski $(1996,2001)$ thinks of intellectual virtues as traits such as intellectual autonomy and courage, intellectual carefulness and fairness, and open-mindedness. 
Aristotle's Phroenesis (defined in Nicomachean Ethics as 'a truth-attaining intellectual quality concerned with doing and with the things that are good for human beings' NE VI. 5.1140b21) is an obvious starting point in a discussion on intellectual virtues since phroenesis mediates between the whole range of moral and intellectual virtues. Aristotle in Nicomachean Ethics differentiates between episteme (scientific knowledge) which relates to the possibility of developing universal explanatory frameworks, techne which relates to technical expertise, intelligence or intuition which refers to immediate perception, wisdom which is the most finished form of knowledge 'knowledge 'complete with head' and phronesis (prudence or practical wisdom) which is the ability to locate the prudent course of action and resist the urgings of the passions and the deceptions of the senses (Aristotle, 1953, 2004, p. 147-154). For Aristotle, the life governed by practical wisdom is one of moral, social, and civic virtue, while the life over which reason alone rules is an amoral, contemplative existence '... it is not possible to be good in the strict sense without practical wisdom, nor practically wise without moral virtue' (Aristotle 1953, cited in Almond 1997, p. 421).

Zagzebshi (1996) makes an important point however that where intellectual virtue is considered, it is usually the Aristotelian virtue of phronesis, or practical wisdom. Zagzebski's aim is not to deny the importance of phronesis but to treat it as a platform from which to consider also other intellectual and moral virtues, which are so important in the creation and sharing of knowledge. Zagzebski 
draws attention to the work of other philosophers in the early modern period who mapped out some of the intellectual virtues e.g., Dewey stressed the place of the intellectual virtues in what he called 'reflective thinking' (Dewey 1933, p.3). The virtues, which Dewey considered most important, are openmindedness; wholeheartedness (when a person is absorbed in the subject); responsibility (to be intellectually responsible is to consider the consequences of a projected step...it secures integrity). More recently, Montmarquet (1986) classified the epistemic virtues of impartiality, or openness to the ideas of others, the virtues of intellectual sobriety (careful inquiry), and the virtues of intellectual courage, which include perseverance and determination. Drawing on Aristotle, Dewey, Montmarquet and others, Zagzebski argues that the intellectual virtues are a sub-set of moral virtues and intellectual virtues are unified by a desire to advance knowledge; there are a few stellar virtues such as such as intellectual originality or inventiveness which relate not simply to the motivation to possess knowledge but to advance knowledge for the human race. (Zagzebski 1996, p. 98).

How might an understanding of intellectual virtues be helpful in analyzing knowledge creation and sharing in organizations? It could be argued at this point that such a virtue-based approach would return the discussion on knowledge to the level of the individual and individual learning and not take account of the social and community aspects of knowledge in organizations; when we think of virtue we think of traditional Greek virtue tradition where the emphasis is placed 
on the inner character of the actor. It is important therefore to stress that all virtues are played out and exist only in social relationships and some virtues in a similar fashion to the social nature of care can be specifically described as relational such as the virtues of openness and responsiveness that are required for a respectful meeting of the other (Benner 1997). MacIntyre's (1981, p. 223) version of virtue ethics is explicit in emphasizing virtues which promote community values and solidarity rather than expressing heroism in the liberal individualistic sense of that term. Here morality is not determined by individual decision-making but has its origins in the social context. A second concern one might raise is the relevance of the discussion on virtue to the contemporary debate within knowledge and organization where so much emphasis is placed on practice, as previous sections demonstrate. However, Zagzebski (1996 p. 180) makes the important point that the intellectual virtues are as crucial in activities or practices such as the arts, crafts, and games. Therefore intellectual virtues are as important to knowing-how as knowing-that: "not only is the distinction between intellectual and moral virtues highly artificial, but the distinction between intellectual virtues and practical virtues needed for things such as creating sonnets, making violins, or winning chess games is artificial as well.' (Zagzebski 1996, p. 180) Finally, virtues that enable the agent to see connections among her beliefs- introspective attentiveness and insights in its various formsare understanding and not just knowledge conducive. A concentration on virtues therefore not only focuses our attention on the relationship between ethics and epistemology but also, attention to Aristotle's phroenesis and Dewey's reflective 
learning, emphasise knowledge that is closer to wisdom (a collection of knowledge about the meaning and conduct of life) than to information and addresses Lyotard's $(984$, p. 18) concern with savoir-vivre (knowing how to live) which surely is central to organizational life and a humanized workplace. Here is but a brief introduction to the intellectual virtues, which deserve detailed attention in terms of how they manifest themselves and if/how, they can be enhanced in communities and organizations creating, and sharing knowledge.

\section{Conclusions and Research Questions}

The thematic review developed in this paper follows the shift from mentalistic approaches to organizational learning, which privileges the individual knower to resource-based approaches to knowledge, which privilege certain categories of knowledge that are likely to yield competitive advantage. More recently, management research emphasizes the fluid, emergent, practice-based aspects of knowledge creation and articulation with the static concept of knowledge being replaced by the more dynamic concept of knowing. Variously influenced by ideas within constructivism, activity theory and communities of practice, management researchers focus on the intricacies of everyday practice and this in turn has led to an emphasis on the narrative, discursive nature of knowing. What is notably absent from the discussion on knowledge and organizations is a consideration of the interrelationship between ethics and epistemology and yet ethical constructs such as care, and trust as well as the presence of intellectual 
virtues, it could be argued, are essential to knowledge creation and sharing. As a starting point to this important area for future research, this paper draws on the intellectual virtues and the work of Aristotle, Dewey and contemporary epistemologists such as Zagzebski. It is important to see virtues not as individual character traits but as relational and to consider how intellectual and moral virtues are exercised in organizational contexts in the generation and sharing of knowledge. How do ethics and epistemology interact in an organizational context? What intellectual and moral virtues might enhance knowledge creation and sharing in organizations? Can organizations in turn encourage the development of these virtues? What of intellectual vices and their detrimental effect on knowledge creation and sharing? How could researchers develop a virtue-based theory of knowledge and organizations? How might other ethical theories enhance our understanding of knowledge creation and sharing?

The interface of ethics and epistemologists would provide a fruitful area of research for those interested in continuing to understand the process through which knowledge is constructed and shared in organizations.

\section{References}

ABBOTT, H. P. The Cambridge Introduction to Narrative. 2002. Cambridge: The Cambridge University Press.

ALMOND, B. 1997. Seeking wisdom. PHILOSOPHY-LONDON-, 72, 417-434.

ALVESSON, M. 1995. Management of knowledge-intensive companies, Walter de Gruyter Inc.

ALVESSON, M. 2001. Knowledge work: Ambiguity, image and identity. Human relations, 54, 863 .

ALVESSON, M. \& KÄRREMAN, D. 2001. Odd couple: making sense of the curious concept of knowledge management. Journal of management studies, 38, 9951018. 
ANDERSON, J. R. 1983. Acquisition of proof skills in geometry. Machine learning: An artificial intelligence approach, 1, 191-220.

ARENDT, H. 1958. The human condition Chicago. The University Chicago Press, 488, $1-101$.

BECKER, S. 1991. Unsupervised learning procedures for neural networks. International Journal of Neural Systems, 2, 17-33.

BENNER, P. 1997. A dialogue between virtue ethics and care ethics. Theoretical Medicine and Bioethics, 18, 47-61.

BERGER, P. L. \& LUCKMANN, T. 2007. The Social Construction of Reality [1966]. Contemporary sociological theory, 43.

BLACKLER, F. 1993. KNOWLEDGE AND THE THEORY OF ORGANIZATIONS: ORGANIZATIONS AS ACTIVITY SYSTEMS AND THE REFRAMING OF MANAGEMENT*. Journal of management studies, 30, 863-884.

BLACKLER, F. 1995a. Knowledge, Knowledge Work and Organizations: An Overview and Interpretation. Organization Studies, 1021-1046.

BLACKLER, F. 1995b. Knowledge, Knowledge Work and Organizations: An Overview and Interpretation. Organization Studies, 16, 1021-1046.

BLACKLER, F. \& MCDONALD, S. 2000. Power, mastery and organizational learning. Journal of Management Studies, 37, 833-852.

BLOOR, D. 1991. Knowledge and social imagery, University of Chicago Press.

BOISOT, M. 1995. Information space: A framework for learning in organizations, institutions and culture, Thomson Learning Emea.

BOLAND JR, R. J. \& TENKASI, R. V. 1995. Perspective making and perspective taking in communities of knowing. Organization science, 350-372.

BRESNEN, M., GOUSSEVSKAIA, A. \& SWAN, J. 2004. Embedding new management knowledge in project-based organizations. Organization Studies, 25, 1535.

BROWN, J. S. \& GRAY, E. S. 1995. The People are the Company. Fast Company, 1, 7879.

BRUNER, J. 1986. Actual minds, possible worlds, Harvard Univ Pr.

CETINA, K. K. 1994. Primitive Classification and Postmodernity: Towards a Sociological Notion of Fiction. Theory, Culture \& Society, 11, 1.

CHARREIRE PETIT, S. \& HUAULT, I. 2008. From practice-based knowledge to the practice of research: revisiting constructivist research works on knowledge. Management learning, 39, 73.

CHOO, C. W. 1996. The knowing organization: How organizations use information to construct meaning, create knowledge and make decisions* 1 . International Journal of Information Management, 16, 329-340.

CHOO, C. W. 1998. The knowing organization, Oxford University Press Nueva York.

CHUN, W. C. 1998. The knowing organization how organizations use information to construct meaning, create knowledge, and make decisions, Oxford: Oxford University Press.

COOK, S. D. \& BROWN, J. S. 1999a. Bridging Epistemologies:The Generative Dance between Organizational Knowledge and Organizational Knowing. Organization Science, 10, 381-400. 
COOK, S. D. N. \& BROWN, J. S. 1999b. Bridging epistemologies: The generative dance between organizational knowledge and organizational knowing. Organization science, 381-400.

CZARNIAWSKA-JOERGES, B. 1997. Narrating the organization: Dramas of institutional identity, University of Chicago Press.

CZARNIAWSKA-JOERGES, B. 1998. A narrative approach to organization studies, Sage Publications, Inc.

CZARNIAWSKA-JOERGES, B., ., U. S. O. E. \& RESEARCH, M. I. O. E. 1993. The Narrative approach to organisation studies, Lund University.

CZARNIAWSKA, B. 1997. A four times told tale: Combining narrative and scientific knowledge in organization studies. Organization, 4, 7.

CZARNIAWSKA, B. 2003. The styles and the stylists of organization theory. The Oxford handbook of organization theory, 237-261.

DAFT, R. \& HUBER, G. 1987. How organizations learn. Research in the Sociology of Organizations, 5, 1-36.

DAY, G. S. 1994. The capabilities of market-driven organizations. the Journal of Marketing, 37-52.

DEWEY, J. 1933. How we think (Rev. ed.). Boston: DC Heath.

DUNCAN, R. B. \& WEISS, A. 1979. Organizational Learning: Implications for Organizational Design. In: STAW, B. (ed.) Research in Organizational Behaviour. Greenwich: CT:JAI Press.

ENGESTROM, Y. 2000. Comment on Blackler et al. Activity Theory and the Social Construction of Knowledge: A Story of Four Empires. Organization, 7, 301-311. 